\title{
Great Toenail Dystrophy: A Single-Center Experience and Review of the Literature
}

Original Article

\author{
Miri Kim, Jin Hee Kang, Baik Kee Cho, Chan Hee Song ${ }^{1}$, Sun Myeong Ock ${ }^{1}$, Hyun Jeong Park * \\ Departments of Dermatology and ${ }^{1}$ Family Medicine, The Catholic University of Korea College of Medicine, \\ Seoul, Korea
}

\section{ABSTRACT}

Background: There have been a few reported cases of congenital great toenail dystrophy (GTND), described as a congenital malalignment of the great toenails. However, acquired GTDN is rare, and has not been documented extensively. This study aimed to describe the clinical features of 21 patients with acquired GTND.

Methods: Twenty-one patients with acquired GTND who visited Yeouido St. Mary's Hospital between June 2005 and August 2012 were retrospectively reviewed.

Results: The mean patient age was 43.1 years (range, 17 to 88 years), and the cohort predominantly comprised women (18/21). In our experience, all acquired GTND patients presented with yellow or yellow-brownish chromonychia, onychotrophy, and onycholysis. Conservative treatment with tape methods and grinding, as well as nail extraction, was provided and yielded little improvement in any case.

Conclusion: This study provides initial data on the nail changes affecting the great toenail, such as yellowish chromonychia, onychomadesis, and onycholysis. These data may help physicians to distinguish various nail disorders, including onychomycosis, congenital malalignment of the great toenails, and yellow nail syndrome.

Keywords: Great Toenail Dystrophy; Yellow Nail Syndrome; Onychomadesis; Onychomycosis; Retronychia

Received: January 30, 2015, Accepted: February 24, 2015

*Corresponding Author: Hyun Jeong Park

Tel: +82-2-3779-1230, Fax: +82-2-783-7604, E-mail: hjpark@catholic.ac.kr

Korean Journal of Family Medicine

Copyright (C) 2015 The Korean Academy of Family Medicine

This is an open-access article distributed under the terms of the Creative Commons Attribution Non-Commercial License (http://creativecommons.org/licenses/by-nc/3.0) which permits unrestricted noncommercial use, distribution, and reproduction in any medium, provided the original work is properly cited. 


\section{INTRODUCTION}

The term 'great toenail dystrophy (GTND)' was first coined by Samman ${ }^{1)}$ in 1978 to describe congenital malalignment of the great toenails. Since then, a few cases involving congenital malalignment of the great toenails (CMGTN), an inherited disorder have been reported; in affected individuals, the longitudinal axis of the nail plate is not parallel to the corresponding axis of the hallux distal phalanx..$^{2-4)}$ Other reported congenital dystrophies present in CMGTN cases include yellowish chromonychia and growth retardation. ${ }^{1,5)}$ However, it has been difficult to find reports of acquired GTND with color and morphological abnormalities. Therefore, we report herein the clinical features of 21 patients with acquired GTND.

\section{METHODS}

A retrospective study was conducted using data from 21 patients with acquired GTND who had visited the nail clinic at the department of dermatology, Yeouido St. Mary's Hospital in Seoul during a 7-year period (2005-2012). Diagnoses were established by a dermatologist on the basis of a clinical examination. Diagnostic inclusion criteria were as follows: (1) acquired color and morphological abnormalities, (2) growth retardation, and (3) negative test for fungal infection of the great toenail. Our study was conducted by analyzing nail charts, clinical images, and patient records (e.g., sex, age, visit date, illness duration, trauma history, previous treatment history, and additional information). Patients with onychomycosis were excluded. To verify that the study patients did not have onychomycosis, a potassium hydroxide $(\mathrm{KOH})$ test, fungus culture, histopathological nail biopsy study, and $\mathrm{KOH}+$ nail clipping + periodic acid-Schiff stain test were conducted.

\section{RESULTS}

Table 1 summarizes the demographic and clinical characteristics of 21 patients with GTND seen at the nail clinic at the department of dermatology, Yeouido St. Mary's Hospital, from June 2005 through August 2012. The 21 patients included 3 men and 18 women, revealing a high prevalence of female patients $(85.7 \%)$. The mean patient age was 43.1 years (range, 17 to 88 years). The highest number of cases occurred among patients aged 20 to 29 years (6/21). The disease duration ranged from 1 to 14 years, with a mean duration of 4.4 years. The mean age at disease onset was 38.6 years. Six patients reported childhood onset, whereas 15 patients had adulthood onset. The mean follow-up duration was 16.8 months. Underlying diseases observed in GTND patients included hypertension $(n=4)$, diabetes mellitus $(n=2)$, mental retardation $(n=1)$, schizophrenia $(n=1)$, and dementia $(n=1)$. Twelve of the 
patients $(57.1 \%)$ had a history of trauma. In addition, 5 of the patients $(23.8 \%)$ had been misdiagnosed with onychomycosis and had been treated with antifungal agents prior to visiting the department of dermatology, without experiencing improvement in their disease status.

Table 1. Demographic and clinical characteristics of the 21 patients with great toenail dystrophy seen at the nail clinic at the department of dermatology, Yeouido St. Mary's Hospital

\begin{tabular}{|c|c|c|c|c|c|c|c|c|c|}
\hline $\begin{array}{l}\text { No. of } \\
\text { patient }\end{array}$ & Sex/age & Duration (y) & Onset age $(\mathrm{y})$ & Follow-up period & $\begin{array}{l}\text { Trauma } \\
\text { history }\end{array}$ & Biopsy & $\begin{array}{c}\text { History of } \\
\text { anti-fungal treatment }\end{array}$ & $\begin{array}{l}\text { No. of nail } \\
\text { t extraction }\end{array}$ & Underlying disease \\
\hline 1 & $\mathrm{M} / 19$ & 14 & 5 & 6 Years & - & + & - & 4 & - \\
\hline 2 & $\mathrm{M} / 65$ & 8 & 57 & 6 Years & + & + & + & 0 & Diabetes \\
\hline 3 & $\mathrm{M} / 22$ & 4 & 18 & 6 Years & + & - & - & 1 & - \\
\hline 4 & $\mathrm{~F} / 52$ & 1 & 51 & 2 Months & + & + & - & 3 & Hypertension \\
\hline 5 & $\mathrm{~F} / 28$ & 1 & 27 & 2 Months & + & - & - & 1 & Gestational diabetes \\
\hline 6 & $\mathrm{~F} / 88$ & 2 & 86 & 1 Month & + & + & - & 1 & Dementia \\
\hline 7 & $\mathrm{~F} / 63$ & 12 & 51 & 1 Month & - & - & + & 0 & Hypertension \\
\hline 8 & $\mathrm{~F} / 40$ & 2 & 38 & 2 Years & + & - & - & 0 & - \\
\hline 9 & $\mathrm{~F} / 23$ & 1 & 22 & 1 Month & - & - & + & 0 & - \\
\hline 10 & $\mathrm{~F} / 87$ & 1 & 86 & 6 Months & - & + & - & 0 & Hypertension \\
\hline 11 & $\mathrm{~F} / 17$ & 4 & 13 & 2.5 Years & + & + & - & 1 & - \\
\hline 12 & $\mathrm{~F} / 53$ & 1 & 52 & 1 Year & + & + & - & 0 & Mental retardation \\
\hline 13 & $\mathrm{~F} / 21$ & 1 & 20 & 8 Months & + & + & + & 0 & - \\
\hline 14 & $\mathrm{~F} / 34$ & 1 & 33 & 1 Month & - & - & - & 0 & - \\
\hline 15 & $\mathrm{~F} / 73$ & 7 & 66 & 8 Months & + & + & - & 3 & Schizophrenia \\
\hline 16 & $\mathrm{~F} / 20$ & 5 & 15 & 1 Year & + & + & - & 0 & - \\
\hline 17 & $\mathrm{~F} / 86$ & 5 & 81 & 1 Year 2 months & - & + & - & 1 & Hypertension \\
\hline 18 & $\mathrm{~F} / 18$ & 8 & 10 & 1 Month & - & - & + & 0 & - \\
\hline 19 & $\mathrm{~F} / 37$ & 4 & 33 & 1 Month & + & - & - & 0 & Endometriosis \\
\hline 20 & $\mathrm{~F} / 39$ & 4 & 35 & 8 Months & - & - & - & 0 & - \\
\hline 21 & $\mathrm{~F} / 21$ & 9 & 12 & 1 Month & - & - & - & 0 & - \\
\hline
\end{tabular}

Figure 1 summarizes the clinical characteristics of the 21 patients' toenails. Fifteen of the 21 subjects exhibited dystrophy of both great toenails, whereas the remaining 6 had dystrophy in only 1 nail. Twenty-one patients (100\%) had yellowish or yellow-brownish chromonychia, onycholysis, a loss of the nail cuticle, and onychotrophy; 17 patients $(81.0 \%)$ had onychomadesis. Tenderness was found in 8 patients (38.1\%), impacted nails in 7 (33.3\%), malalignment in $6(28.2 \%)$, onychogryphosis in 6 (28.2\%), ingrown nails in 6 (28.2\%), shrimp nails in 3 (23.8\%), and chronic paronychia in 4 (19.0\%) (regarding shrimp nails, $\geq 3$ nail plates were attached to the nail bed and exhibited transverse nail ridges, resembling the back of a shrimp). Furthermore, 2 patients (9.5\%) with retronychia, 1 patient (4.8\%) with a green nail, and 1 patient (4.8\%) with subungual hemorrhage were observed. 


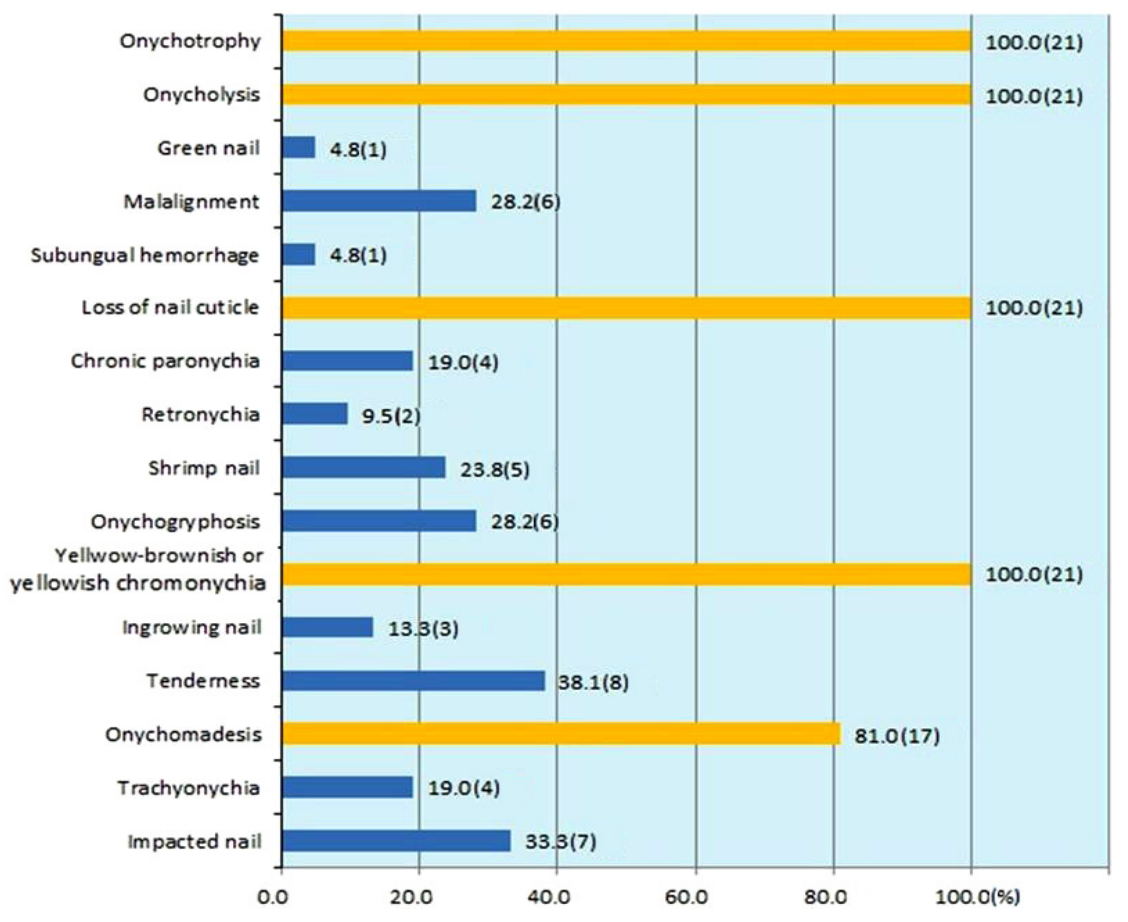

Figure 1. Clinical features of nail changes for the 21 patients with great toenail dystrophy seen at nail clinic of the department of dermatology, of Dermatology, Yeouido St. Mary's Hospital. Values are presented as \% of patients (no. of patients).

For treatment, 7 patients (33.3\%) underwent nail extraction at the nail clinic at the department of dermatology, Yeouido St. Mary's Hospital. Nail extraction was performed once in 4 patients (19.0\%), 3 times in 2 patients (9.5\%), and 4 times in 1 patient (4.8\%); however, the lesions did not improve during a mean follow-up period of 23.6 months.

\section{DISCUSSION}

This study report describes the first large-scale series of acquired GTND cases. In our study, all patients with acquired GTND presented with color changes of the great toenails to yellow or yellowbrown, accompanied by growth retardation (Figure 2). These findings, however, are also observed in patients with other nail diseases. 


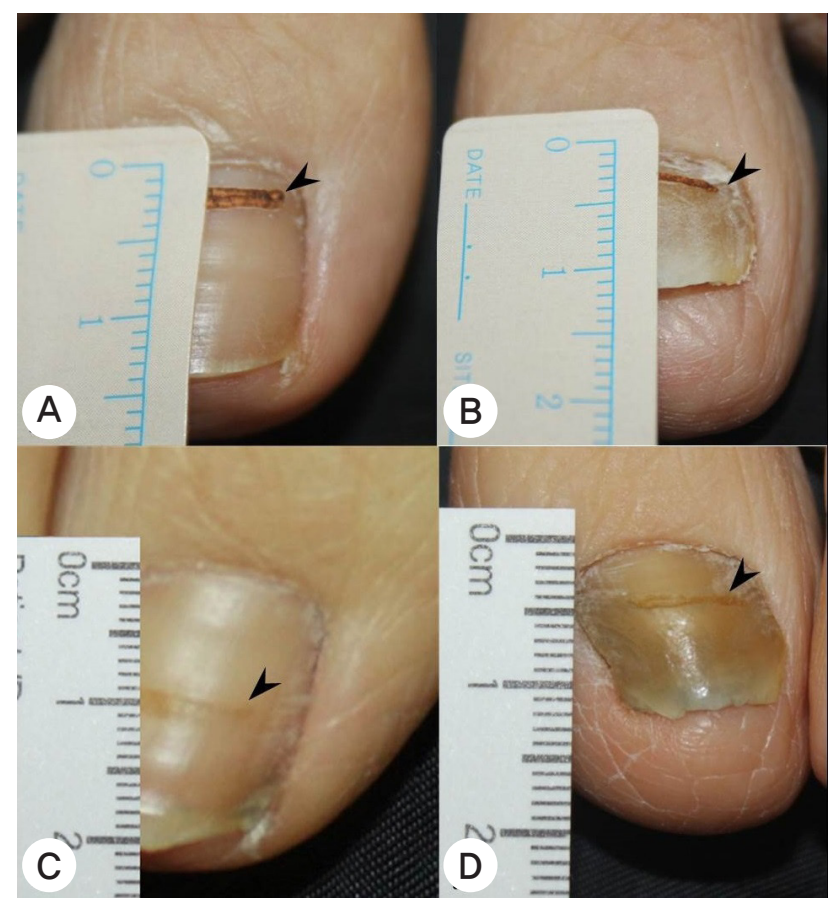

Figure 2. (B, D) Great toenail dystrophy of left great toenail presenting growth retardation compared to $(\mathrm{A}, \mathrm{C})$ normal right great toenail during 4 months. Arrow head is a CO2 laser marking (case 19).

Yellow nail syndrome should be considered in the differential diagnosis, as it features the same characteristics. Yellow nail syndrome, a rare disorder of unknown etiology, has 3 characteristic signs, including yellow to yellowish-green nail discoloration, lymphedema, and chronic respiratory disorder.") However, it differs from GTND in that all nails exhibit yellow discoloration.

In our study, all patients had yellowish or yellow-brownish chromonychia, onychotrophy, and onycholysis, which can also be observed in patients with onychomycosis. ${ }^{4,7)}$ Five patients (23.8\%) were misdiagnosed with onychomycosis and were treated with antifungal agents that did not improve their lesions. As GTND may be misdiagnosed as onychomycosis, a differential diagnosis can prevent unnecessary treatment.

Among the 21 studied patients, 17 also presented with onychomadesis (Figures 3, 4) due to nail plate growth discontinuation as a result of transient nail matrix dysfunction. Generally, drug rash, acute paronychia, and nail matrix trauma are common etiologic factors of onychomadesis. ${ }^{8)}$ Interestingly, 12 of these 17 cases reported a history of trauma; however, trauma could not be excluded in the remaining 5 cases, as the patients could have easily been exposed to trauma in many situations not usually recognized by patients, such as wearing tight shoes and compromised cognitive functions (mental retardation, schizophrenia, and dementia). Physical trauma might have been a predisposing factor for the development of onychomadesis. Therefore, it is presumed that onychomadesis may be related to trauma. Accordingly, it may be an important factor for inclusion in further studies regarding the etiology of acquired GTND. 


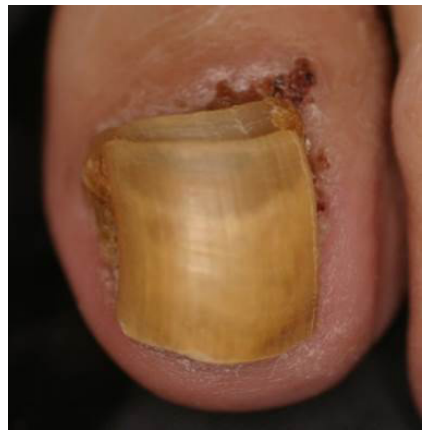

Figure 3. Great toenail dystrophy presenting with onychomadesis, onycholysis, retronychia, loss of cuticle and yellowish chromonychia. Proximal ingrowth of the nail causes a persistent proximal nail fold inflammation and granulation tissue formation (case 6).

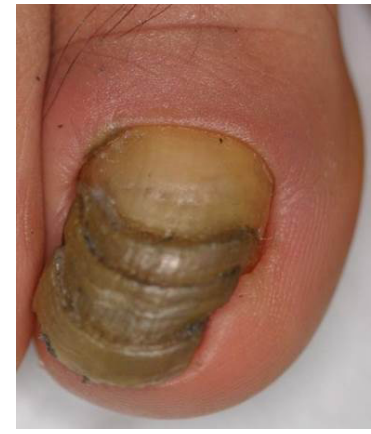

Figure 4. Great toenail dystrophy with shrimp nail, malalignment, onychotrohy, onychomadesis, onycholysis, loss of cuticle and yellow-brownish chromonychia (case 2).

We first defined the term 'shrimp nail' as a bent nail plate with an appearance similar to the curved back of a shrimp. In our study, 5 patients (23.8\%) presented with shrimp nail (Figure 5). Shrimp nail has been described as a nail in which repeated onychomadesis occurs before sufficient regeneration of the new nail is completed. This repeated onychomadesis creates several ridges. As the distal nail plate caves into the soft tissue at the end of a toe, the nail plate undergoes severe vertical curvature to resemble the back of a shrimp.

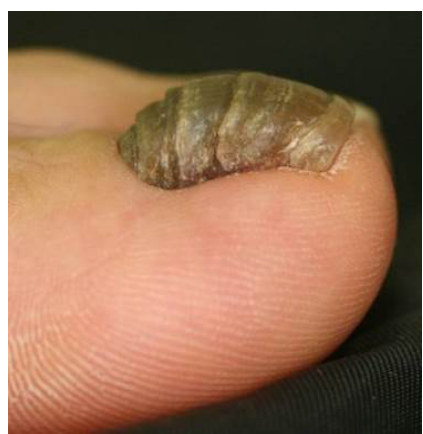

Figure 5. Great toenail dystrophy presenting with shrimp nail, onychomadesis, onycholysis, loss of cuticle and yellow-brownish chromonychia (case 20).

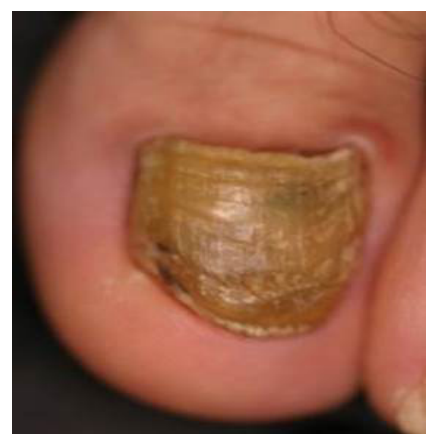

Figure 6. Great toenail dystrophy with retronychia, onychomadesis, onycholysis, loss of cuticle, impacted nail and yellowish chromonychia (case 3 ).

Two patients (9.5\%) with retronychia were also observed (Figures 3, 6). Recently, de Barker et al. ${ }^{9}$ defined retronychia as a proximal ingrowth of the nail that occurs when the nail embeds backwards into the proximal nail fold. This phenomenon can lead to persistent inflammation of the proximal nail fold and cause pain, along with granulation tissue formation. ${ }^{9)}$ Among the female patients in our study, persistent proximal nail fold inflammation and painful granulation tissue were generated as a result of persistent trauma induced by a lifestyle in which high-heeled shoes were worn. 
Six patients (28.2\%) with acquired nail malalignment, accompanied by onychotrophy were observed (Figures 7, 8). Children affected by CMGTN innately develop lesions that have been reported to resolve spontaneously with age. CMGTN was not observed in our study, and none of the patients experienced a natural resolution.

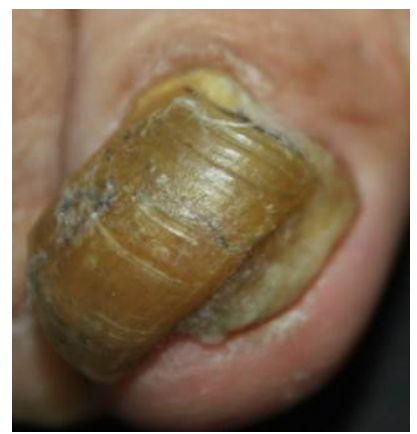

Figure 7. Great toenail dystrophy with malalignment, onychotrohy, onycholysis, loss of cuticle and yellowbrownish chromonychia (case 12)

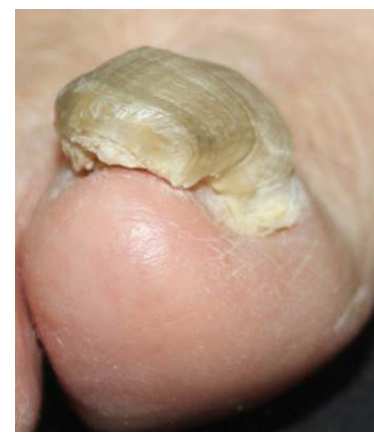

Figure 8. Thickened great toenail dystrophy presenting with onychotrophy, onycholysis, loss of cuticle and yellowish chromonychia (case 15)

Little is known about the pathophysiology of GTND. In yellow nail syndrome, the phenomena of nail thickening, discoloration, and growth retardation are presumed to be caused by a disturbance in lymphatic drainage near the nails. ${ }^{6,10)}$ However, the definitive cause of yellow nail syndrome has not yet been elucidated. Further investigation is needed to determine whether the mechanism of GTND, which presents with growth retardation and yellowish chromonychia, is the same as that of yellow nail syndrome. We assume that variations in the abnormal nail findings are caused not only by trauma to the nail matrix area, but also by improper disease treatment and management.

In our study, the underlying diseases present in affected patients included hypertension, diabetes mellitus, mental retardation, schizophrenia, and dementia. In cases involving compromised cognitive function (e.g., mental retardation, schizophrenia, and dementia) along with mobility issues, patients might easily be exposed to trauma of the toenails, thus increasing the possibility of developing GTND.

An effective treatment for acquired GTND has not yet been established. In our study, several treatments, such as education regarding the avoidance of tight shoes, tape methods, nail extraction, and grinding were conducted, none of which were particularly effective. Although prior studies reported natural recovery from congenital GTND, we did not observe natural recovery in our patients with acquired GTND.

Our study has several limitations. First, the characteristics of a retrospective study lead to the possibility of inevitable bias. Our study included a limited number of patients and could not suggest a disease etiology or effective treatment method. However, this study demonstrated the clinical characteristics of acquired GTND, which was accompanied by neither systemic symptoms nor fungal infection. Acquired GTND has its own distinct characteristics in contrast to CMGTN, including a history of trauma in most cases. Therefore, we can assume that nail matrix trauma is among the most important predisposing factor of acquired GTND. Our study was designed to provide insight into the 
clinical manifestations of acquired GTND to enable differential diagnoses including onychomycosis, yellow nail syndrome, and CMGTN. Further studies of the pathophysiology and treatment of acquired GTND are needed to suggest a disease etiology or effective treatment methods.

In our study, all acquired GTND patients presented with yellow or yellow-brownish chromonychia, onychotrophy, and onycholysis, as well as growth retardation. These findings are also frequently observed with onychomycosis. Therefore, a differential diagnosis of onychomycosis should be considered to avoid unnecessary treatment with antifungal agents.

\section{CONFLICT OF INTEREST}

No potential conflict of interest relevant to this article was reported.

\section{ACKNOWLEDGMENTS}

This research was supported by Basic Science Research program through the National Research Foundation of Korea funded by the Ministry of Education, Science and Technology (2012046972).

\section{REFERENCES}

1. Samman PD. Great toe nail dystrophy. Clin Exp Dermatol 1978;3:81-2.

2. Great toe-nail dystrophy. Br J Dermatol 1989;120:139-40.

3. Handfield-Jones SE, Harman RR. Spontaneous improvement of congenital malalignment of the great toe nails. Br J Dermatol 1988;118:305-6.

4. Wagner G, Sachse MM. Congenital malalignment of the big toe nail. J Dtsch Dermatol Ges 2012;10:326-30.

5. Dawson TA. An inherited nail dystrophy principally affecting the great toe nails. Clin Exp Dermatol 1979;4:309-13.

6. Hoque SR, Mansour S, Mortimer PS. Yellow nail syndrome: not a genetic disorder?: eleven new cases and a review of the literature. Br J Dermatol 2007;156:1230-4.

7. Westerberg DP, Voyack MJ. Onychomycosis: Current trends in diagnosis and treatment. Am Fam Physician 2013;88:762-70.

8. Mehra A, Murphy RJ, Wilson BB. Idiopathic familial onychomadesis. J Am Acad Dermatol 2000;43(2 Pt 2):349-50.

9. De Berker DA, Richert B, Duhard E, Piraccini BM, Andre J, Baran R. Retronychia: proximal ingrowing of the nail plate. J Am Acad Dermatol 2008;58:978-83.

10. DeCoste SD, Imber MJ, Baden HP. Yellow nail syndrome. J Am Acad Dermatol 1990;22:608-11. 